\title{
The Conception of Risk in Minority Young Adolescents Aged 12-14 Years
}

\author{
Raymond Leblanc $^{1, *}$, Marie Drolet ${ }^{2}$, Daphne Ducharme ${ }^{1}$, Isabelle Arcand ${ }^{1}$, Robert Head ${ }^{1}$, \\ Jean R. Alphonse ${ }^{1}$
}

${ }^{1}$ Faculty of Education, Ottawa University, Canada

${ }^{2}$ Faculty of Social Sciences, Ottawa University, Canada

Copyright $(\mathcal{C} 2015$ by authors, all rights reserved. Authors agree that this article remains permanently open access under the terms of the Creative Commons Attribution License 4.0 International License.

\begin{abstract}
This study examines the conceptualization of risk behavior held by 26 Franco-Ontarian young adolescents (12-14 years of age) who participated in Lions Quest, a program specially designed to promote physical and mental health and to prevent drug and alcohol use. More specifically, it seeks to better understand the participating adolescents' conception of risk and protective factors in a linguistic minority context, with the eventual purpose to prevent or delay alcohol and drug use. A qualitative methodology mainly based on semi-structured interviews generated discussion around a variety of dimensions related to risky behaviors, extreme and dangerous risks, positive and negative risks, social and physical risks. The adolescents hardly mentioned drug, alcohol, and cigarette use. However, they were aware of the risks of consumption and dependence.
\end{abstract}

Keywords Risk $^{1}$ Behavior, Adolescence, Minorities, Prevention

\section{Introduction}

Conceptions of risk by young adolescents change with the times in which they find themselves and is lived through the youthful lenses of their versions of modernity. The sociologist Zygmunt Bauman speaks to this as liquidity of modernity [1]. The cumulative effects of exposure to cultures of risks and their liquidizing effects on modernity can be devastating. Adolescence, as lived in a consumerist 'now-ism', can lead to risk taking. Through the corporate sham of consumerist trending and instant gratification, adolescent identity formation can be perverted towards

1 Peretti-Watel [7] reported as etymological root for risk: "comes from the Italian Risco (or Spanish riesgo), words derived from Latin reecum ("those which cut") to first identify the dangers posed to vessels, and more generally any danger for sea merchants... Another etymological possibility being the Roman rixicare ("To desire", which leads to a "brawl"), also evoking danger" (p. 6-7) increased risk-taking and the development of anti-social behaviors $[1,2]$.

With the erosion of our senses of selfhood, we have instead rushed towards substitutes that can almost erase the feelings associated with taking risks with our physical and emotional selves and others. We have raced to embrace adolescent [and adult] morbidity and mortality, whether through the excesses of culturally supported childhood obesity, the consumption of alcohol, smoking tobacco products, or other recreational drug misuse. The related mental health problems, medical problems issuant from unsafe sex, personal and public dangers of risky and unsafe driving, and the growing cultures of gun and other violence rip at the social fabric that has previously held us fast and strong. It is the emergence of prevention science since the 1980 's that has to a small degree mitigated some measure of these problem behaviors [3]. However, without wanting to sound particularly alarmist or socially shrill, the limits of our societal dams to hold liquidized risk, to address these risky behaviors, are already well past being breached. Never mind who is minding the store, who is minding our children - our future?

Recently, Moati and Peretti-Watel [4] argued that prevention measures can reduce, mitigate or eliminate a certain number of risks. Other research in prevention also identifies age-related spikes in impulsivity and risks that threaten [sometimes fatally] the well-being of adolescents [5]. However, there remains hope for adolescents to avoid the dangers posed by many risks, as they form their identity. Heightened interaction between individuals and others within social contexts - seems to enhance Health Related Quality of Life [HRQOL] [6]. Adolescence is a life phase where we as individuals are able to sort who we are as young adults and orient our relationship to our world, towards a 'more realistic' journey into adulthood. There is no free lunch, we pay for and learn from our mistakes, and the risks we sometimes take, in our varied relationships [6]. This period of sampling through potential mistakes and risk can be influenced by external social and cultural values [7].

The purpose of this study is to better understand risk, in a 
context of the adolescent experience of participation in a life skills program (Lions Quest Skills for Adolescence).

The framework for the study is built up around reviewing relevant literature and studies of adolescent risks factors, and sharing key findings in part discovered through student participant interview discussions, and conducting an analysis of the related study data. Proceeding from an examination of the conception of risk in adolescents, through an ecological perspective, findings, an overall discussion, and some conclusions will be presented.

\subsection{Theoretical Framework: An Ecological Lens}

To frame risky behavior in adolescence, we adopted an ecological approach, an approach which recognizes the roles of environments in which behaviors occur. In the case of Lions Quest program, it aims to foster an environment which seeks to eliminate, or perhaps more realistically, somewhat minimize exposure and engagement in risk-taking behaviors through education and awareness, as these are types of preventative and interventionist actions which have been claimed to mitigate incidences of association and risk behavior/injury [8].

Parents can play a sometimes pivotal role in enhancing any effects of interventionist and preventative programming, particularly as they proceed from positions of trust and caring, to engage their adolescent children in ongoing discussions about social risk-taking behaviors and decision-making skills development $[9,10]$. And, of course, optimally, under the ecologically watchful eyes of caring parents, adolescents can make the occasional misstep, and be able to count on corrective parental guidance.

Why do adolescents take risks? The ecological perspective suggests a range of factors which influence behavioral changes observed in youth. Three vantage positions that adolescents may adopt include a traditional outweighing of risk, rewards, consequences; behavior that reflects a greater propensity towards acting impulsively or emotionally; and more maturely through careful deliberation and informed decisions where risk-avoidant values are effectively considered and adjusted considerations taken into account [11]. For students belonging to the foremost group, the highest risk takers, programs like Lions Quest can mitigate such maladaptive behaviors and help to create a more positive experience of high school life for such students [12].

\subsection{Background: Adolescence and Risk}

There are two facets of identity development - identity formation which includes commitment making and identity synthesis, and identity content, which involves moral or character development. Either facet can act to protect or risk possible health outcomes, this being largely dependent upon the psychological maturity or diffused immaturity of the individual $[13,14]$.

Sometimes, people who engage in risky behaviors seem to do so for elusively ulterior motives: seeking to satisfy a curiosity, to simply experiment, for thrill-seeking, testing of personal limits, or perhaps a need to challenge [15].

A contemporary perspective of the study of risk and prevention in the second half of the $20^{\text {th }}$ century is discussed by Werner [16]. A number of seminal studies such as Garmenzy and Rutter's longitudinal studies, and their subsequent research [17] moves away from retrospective to prospective perspectives, and later informs resilience and success despite/through adversity [18, 19]. From an epidemiological perspective, it is important to note variables that predict problem behaviors or their manifestation, and environmental barriers such as poverty and dependency problems of parents. These studies are primarily based on calculations of probability measures [20].

Some vulnerabilities associated with risk-taking are likewise linked to child protection, particularly as influenced by abuse, neglect, exploitation, violence, and poverty. Cycles of harmful attitudes and risky behaviors run generationally, including the influences of parental dysphoria, conjugal, interpersonal and other violence [21, 22]. Even before birth, children are exposed to stressors, which, when combined with later health, educational, and socioeconomic conditions, can result in an increased risk of engaging in risky-behaviors, including escapist behaviors such as drug use [23, 24].

In adolescence, risk taking does occur, and perhaps more so when friends are present. It is no secret that trying to impress friends or peers is a factor in deciding to engage in risk-taking [25]. Popularity is frequently associated with propensities towards taking risks, and vice versa. Surely this is not done blindly, but rather is willfully determined by the adolescent [7]. Carelessness can seem to reflect overconfidence, optimism, delusions of control, or feelings of invulnerability. Further, compounded with youthful misconceptions of invulnerability and alcohol or substance abuse, further debilitates decision making abilities. It is no wonder that a considerable component of injury amongst adolescents is resultant of taking risks [25].

Why is risk-taking so prevalent during this period of life? This period of life is full of positive challenges and risk taking is very common. Most young people do understand the serious consequences of certain dangerous and risky behaviors [15]. Deliberate risk taking happens more often with boys than girls [7], stemming from school disconnectedness and peer pressure [25]. For boys, risk-taking can be an engine of identity construction when the youth is involved with peers in activities that represent a challenge [26]. Also, risk-taking can be a way to stand out, to be distinguished. For example, for some adolescents, smoking a cigarette is a symbol of rebellion or independence. The presence of peers potentially doubles risk-taking in playing video games, and potentially results in negative reinforcement [27]. Quite eloquently, Peretti-Watel and Moati [4] address adolescent decision-making and risk taking as:

"Adolescents construct their identity and gain status 
among peers through transgressive experiments: refuse to drink and smoke, and they expose themselves to a group sanction, risking identity and being stigmatized. When they engage in risky practices, it is not necessary to consider that they are passive victims of peer pressure or mimetic impulses: instead these practices may well be considered as the result of a compromise between competing risks, performed by an individual actor who makes decisions and assumes a role." [4, p. 67, free translation from French].

Significant brain development, in particular frontal lobe growth associated with reasoning, risk assessment and logic, takes place during adolescence. Neuroscience informs us that judgmental capacities for adolescents are affected during this period of frontal lobe growth [28]. Recently, neurodevelopmental hypotheses have proposed that a hyper-sensitivity between the two brain lobes enhances and reinforces anticipated rewards from taking risks [27]. According to Steinberg [29] the highest levels of risk for adolescents are the result of a competition between the socio-emotional network and cognitive control networks which develop according to different rates of maturation. In early adolescence, the socio-emotional system is dominant and it is only gradually that the system of cognitive control moderates risk taking. Only 3 to $5 \%$ of adolescents are depressed and nervous, putting them at risk of drifting into extreme behavior [30].

When it comes to alcohol consumption, for example, we now know that [a common early experience of ] exposure to cultures of consumption, as well as the disease of alcoholism or abusive and/or problem drinking by a mother, can significantly and negatively impact an adolescent's propensity to engage in risky alcohol consumption behaviors [31]. So too can feelings of disconnectedness towards school and living in communities that are considered unsafe - such as 'ghettos' - lead to increased vulnerabilities to alcohol abuse, drug abuse and other high risk behaviors, whereas the opposite can occur for those belonging to peer groups with positive attitudes geared towards behavior that would break negative normalized and risk-taking tendencies, with the caveat that high impulsiveness levels are considered as a factor in increasing probabilities for alcohol consumption and drug use/abuse amongst adolescents [32].

Some recent studies have reported a worrying increase in the consumption of alcohol and cannabis amongst adolescents [33]. In Canada, more than $20 \%$ of grade 10 students report drinking alcohol weekly [34]. In Francophone Ontario, 52\% of young adolescents report having consumed alcohol in the year preceding our study [35]. In the rural region of Prescott-Russell, these numbers climb even higher; $75.4 \%$ of adolescents from grades 7 to 12 say they have previously consumed alcohol [35].These statistics correspond with American data reporting on rural youth alcohol consumption [36] and that for outlying suburban areas [37], which are the two most at risk communities for [binge] consumption [38]. Why? Numerous studies suggest that is because these youths are more likely to engage in consumption during festive occasions and in excessive quantities.

Only a fraction ( $6 \%$ to $12 \%$ ) of adolescents develop problems that meet the criteria for dependence, alcoholism or addiction requiring treatment or which affect their daily ability to function successfully [39]. Contradicting the EMCDDA [33], the 2005 U.S. National Survey on Drug Use and Health informs us that the trend towards alcoholism and drug use is downward for marijuana use among 12-17 year olds, from a reported 8.2 percent in 2002 to 6.8 percent in 2005 and further declines from 11.6 percent in 2002 to 11.2 percent in 2003, 10.6 percent in 2004, and 9.9 percent in 2005 , for illicit drugs (hard drugs such as methamphetamine, ecstasy, cocaine, crack, etc.) for this group of adolescents [40]. The simple fact that 12-17 year olds are engaging in risky behaviors that include using marijuana, cocaine, crack, ecstasy, methamphetamines or other drugs is worrying in and of itself. This does not diminish the riskiness of consuming alcohol, and there is always the consideration of adolescents who mix alcohol with drugs. Such behaviors raise important issues for public health because of the risks taken in such circumstances.

Further recent studies show that the average age for first time experiencing of marijuana in the U.S.A. is 14 years old (a worrying situation) and that the first time for youths to consume alcohol is under 12 years of age. As for hard drugs, the results of a survey show that among Canadian students in Grade $10,50 \%$ of boys and $40 \%$ of girls have tried alcohol and drugs [34]. In Ontario, 25.6\% of high school students have consumed marijuana in the year preceding a recent study [41]. In the region of Prescott-Russell, $14.2 \%$ of 10 th Grade students and $18.9 \%$ of Grade 12 students have consumed marijuana. The Prescott-Russell statistics may also reflect increased consumption and experimentation levels reflective of adolescent risk-taking behaviors associated with being from a minority [language] population.

Much of the existing research addresses population pockets, which might present misdirected views and significant statistical variations of adolescent propensities towards risk-taking. Alcohol and cannabis consumption is not unique to outlying suburban and [economically challenged] rural young adolescents. Urban and affluent children who are under pressures to achieve and succeed while being isolated from their parents can also manifest serious elevated levels of consumption and use for both alcohol and drugs [42].

In 1938, actor Spencer Tracy played the role of Father Edward J. Flanagan, in the popular biographical drama film "Boys Town", and famously believed that there was no such thing as a bad boy. More recently, Levesque [43] debunked the myth that troubled children grow to become troubled adolescents. Apparently, "normal" adolescents are, as a group, well-adjusted and positively engaged, suggesting those who are not "normal" require some form of treatment. Of course, the caveat here is accepting a blanket definition of "normalcy". Decelerated adolescent risk-taking is associated with emergent levels of maturity [6]. 
In a perfect world, "the onset of adolescence also marks a change in patterns of social behavior...A more fully integrated social identity emerges...At the end of adolescence, an individual is expected to emerge as a socially capable adult." [44]. However, for many adolescents, it is not such smooth sailing, and reports of frequent anxiety or depression doubled between 1986 and 2006 [45].This has resulted in increased engagement in risky sexual behavior $[46,47]$.

Adolescents experiencing high levels of anxiety may be experiencing problems with school adjustment or serious family problems and already have dependency problems [29]. Some may have deviant personality types. Psychosocial resources such as environmental supports and personal resources may provide empowering skills and facilitate coping mechanisms kicking in, for these adolescents [48]. This is not an instant process, but one of accumulated empowering through consistent and varied supportive efforts [49]. It is not such a stretch to realize that perceived self-efficacy plays a pivotal role in this formative process [50].

\subsection{Objective}

Given that risky behaviors are commonplace in adolescence, it is extremely helpful to better understand the conceptions of risk for adolescents to better address the conditions and judgments that lead to risk taking by adolescents [51].Thus, in this study, we aim to make sense of how young teens decide upon risky behaviors, their awareness of risk, and their feelings associated with risk, following a participation in the "Lions Quest Skills for Adolescence" program. We hope to generate further inquiry into this important field of study.

\section{Research Design}

\section{1. "Lions Quest Skills for Adolescence (LQSA)" Program}

This study of the conception of risky behaviors was conducted in three schools located in Eastern Ontario, with teenagers aged 12-14 years who participated in the "Lions Quest Skills for Adolescents" program. The schools included an elementary (K-8) French public school, a middle school (grades 7 and 8) French Catholic school, and an elementary (K-8) English public school with a French Immersion program in place.

The program promotes physical and mental health in order to prevent or reduce alcohol and/or drug consumption by teens. The LQSA's program "Life Skills for Adolescents" is recognized by the U.S. Department of Health's Center for Substance Abuse Prevention [52]. The program's objectives are for youths to: 1) learn to be more assertive or self-confident, manage their emotions and resist peer pressure; 2) develop a greater sense of responsibility; 3) improve their conflict resolution skills; and 4) improve their intervention skills for peers who start to consume or engage in other risky behaviors (http://lions-quest.org/substanceabuse.php). The program, which provides a basis for adolescents to experience a more positive and healthy social development, includes activities that provide opportunities to schools to reinforce positive behaviors for young people. By developing these social skills in adolescents, in this study among young people aged 12-14 years, the program will achieve its longer-term goal of preventing or delaying risk-taking behaviors such as the consumption of alcohol and drugs during adolescence.

The objectives set out in the program Life Skills for Adolescents state as their aim to ensure that students learn to build confidence, to make responsible choices, defend their opinions, improve their relationships with others, to think about risks and their consequences, resolve conflicts, learn responsibility, and to make positive health choices.

Risk is one of the five major themes of the program. The following questions on risk taking are addressed in the training program: What risks to take? What risks to not take? Why or why not avoid a risk? The program activities examine the influence that others can have on risk taking, for example, peer pressure and the influence of advertising. Positive and negative risks are discussed in view of the discovery of the world and oneself.

\subsection{Participants}

Students were invited to participate in this study through the secretariat of the schools involved, who emailed a letter outlining the program and a consent form to parents of all former 7th grade program participants. Twenty-six (26) adolescents agreed to participate, with the consent of their parents. This sample is a quota sample, as defined by Mayer et al. [53]. Indeed, to facilitate a range of respondents, we finally met in interview 9 Francophone students in Grade 8; 8 Francophone students who were in Grade 7; and 9 Anglophone students in Grades $8 \& 9$ who participated in the same program, in English.

According to the study demographics, the adolescents who participated in this study came from two-parent families with both parents working. The parents' education levels varied from secondary school to graduate university studies. They were equally distributed as living in the country, suburbs, town and city. All of the students who completed the demographic portion of the study were born in Canada and considered themselves to be native bilingual Canadians.

Adolescents interested in participating in this study were asked to contact one of two research assistants responsible for conducting data collection. Subsequently, a meeting was planned at a time convenient to the student, taking place at their school. At this meeting, the research assistant again reviewed and further explained the nature and format of the study for the participants, answering any questions asked by the potential participants, who were then invited to sign a consent form, in full compliance with the requirements of the 
Ethics Committee for Research in Social and Human Sciences. The assistant then proceeded to collect qualitative data via a semi-structured interview that lasted between 45 and 60 minutes. These interviews were audio recorded for later analysis. At the end of the interview, participants were presented with a token honorarium in the amount of $\$ 25$ for their participation.

\subsection{Data Collection}

The main strategy for data collection was qualitative semi-structured interviews. The purpose was to gather data on perceptions of risky behaviors for adolescents by asking the following guided interview questions that took on average 15 minutes:

(1) Do you know people who have extreme behavior and take dangerous risks?

(2) What do they do? Would you take those risks?

(3) Did you think the same a year ago? (If there is a difference, is it because of the program? Life Skills for Adolescents?)

(4) Do you smoke? If yes, since when? How did you start? If not, why?

(5) Do you know people who use drugs? What do you think about that?

\subsection{Data Analysis}

All interviews were transcribed verbatim and analyzed using the program N-Vivo 8 [54]. They were codified by a process of data reduction, data display and conclusion drawing or verification [55, 56]. Results were analyzed deductively and inductively. Grid categories related to positive and negative, social and physical risks served as initial categories. These grids were established based on an inter-rater dyad where some of the material was read independently by the co-researchers and five graduate students. Grid categorization was subsequently established by consensus. Three graduate students completed the codification. The method of data interpretation followed a pattern coding process [55].

\section{Findings}

Considering the overall conception of risk of the 26 adolescent participants, differences were observed between the nine boys and seventeen girls. For young people of both sexes, extreme behavior or risk first refers to the practice of a dangerous sport such as skiing, skateboarding, and jumps in general (parachute or bicycle). As one youth explains it: "Well! Extreme behavior makes me think of... like jumping off or doing something dangerous... My friend likes to take jumps and stuff. So I guess that is a little risky if you don't know what you are doing..." (Student - Grade 7, translated from French). Secondly, extreme behavior or risk is doing something harmful to health, such as drug use or smoking:
"An extreme behavior, I think, is doing drugs" (Student Grade 7, translated from French). One student finds that acting against the established rules or doing illegal things may also be characterized as extreme behaviors or risk can include being rude to a teacher: "Well, one of the boys in my class, he takes risks by sort of mumbling after the teacher talks to him. Sort of angry." (Student - Grade 7).

There are differences between boys and girls. For the boys, hurting someone - for no apparent reason, while playing a sport or as a result of anger can be considered an extreme behavior or risk. A student recounts: "I think extreme behaviors would be people who take things out of hand, like for example the guy who punched me. I think he completely exaggerated everything" (Student - Grade 8). Girls seem to be more affected by the risks associated with relationships between them and others - these risks are perceived as positive or negative. For example, several girls reported as positive risk announcing their feelings for others [romantic]. The girls seem to avoid to a greater extent taking emotional risks for fear of being injured or injuring someone else, such as taking the first step in a relationship, openly expressing their feelings or opinions, or "...like things that might get you in trouble or your friends may not be pleased with or someone might not be pleased with." (Student - Grade 8).

Young adolescent participants spontaneously identified different types of risk either as social risks or/and physical risks. For example, social risk: respondents speak of disrespect, gossip or being made uncomfortable: "Since this year, I go in front of the class.... I do radio, now." (Student Grade 8, translated from French). Hurtful words addressed to others, demonstrating a lack of respect and gossip are reported: "Well there's people in our class that like really lash out sometimes and they'll say really nasty things. [...] Yeah but they don't just yell at them, they say things that are just really unneeded." (Student - Grade 8). Students often named physical risks as dangerous challenges [daredevil-types of activities]. For example, a student demonstrates an awareness of what dangers risk can pose by reflecting the objective of the program: "One of my friends, for some reason, he enjoys climbing things, like school, and I have no idea why. He enjoys fire, I don't know. " (Student Grade 9).

Our interviews suggest that the risks associated with alcohol, tobacco or drugs do not seem problematic in this age (12 - 14 years), in the region where the study took place. The great majority of respondents said they were not exposed to consumption outside of their family. They report having observed their family members smoke cigarettes or drink socially and some took a sip of alcohol while they were on holiday with their parents. Two youths who identified consumption as risky had heard of a friend of a friend who used marijuana. That said, some students believed that consuming alcohol is unavoidable - an eventuality that they might likely consume before the end of high school. "I would drink, but never smoke. Because smoking damages your lungs and can kill you... Everyone, almost everyone drinks." (Student - Grade 8, translated from French). Thus, 
according to the respondents' risk-taking associated with alcohol consumption, any potential incidence for tobacco or drugs use seems low for this group of study participants. Many of them report a very negative attitude towards smoking and drugs. They recognize the risk of consuming, and do not seem willing to take the risk of smoking cigarettes or cannabis. They explain that it is makes no sense to them, and it is unhealthy to smoke or take drugs: "No thanks, that's gross, I'll die." (Student - Grade 8). However, they seem to think that drinking alcohol is much closer to their social reality, and stated that they may consume alcohol prior to the end of high school.

The adolescent participants divided risks into positive and negative risks. Positive risks appear to be associated with positive consequences such as the successful completion of an activity, and satisfaction (e.g. student radio has already been mentioned or ski jumping). Negative risks with downsides are associated with adverse consequences for health and well-being, such as consuming alcohol, tobacco or drugs. For most students, these risks do not seem to be part of everyday life. One student-reported example of negative risk was " "A negative risk, however, could be taking drugs, drinking alcohol." (Student - Grade 8, translated from French). Other students made connections between physical activity and negative risks. A Grade 8 student identified skateboarding as a negative risk, because it is an activity where he could get hurt. "Yes. When he's skateboarding, he is doing full of stuff there, and he hurts himself... He did it all the time wrong. " (Student - Grade 7, translated from French). Another student described negative risks taken by a classmate. "He throws things and he punches me all the time." (Student - Grade 7, translated from French). Or, some risks can be seen as both positive and negative ... This same student, considers self-expression as both negative and positive risk. He mentioned that: "When you give your opinion to someone. I'm always afraid of that. So, it could be a positive risk, but a negative risk at the same time." (Student - Grade 8, translated from French).

Several factors affect decision making for adolescents regarding whether they choose to engage in risky behaviors or not. The three most obvious factors, as reflected by interviews of adolescent participants, are the influence of parents, their peers, as well as the program Life Skills for Adolescents. Comparing the influence of parents and peers, a student in the 8th grade mentioned: "Sometimes, I decide to talk first to my friends, and after to my parents. "(Student Grade 8, translated from French). For adolescents, the program helped them to begin thinking about how peer pressure can occur and how to counter this pressure as shown in answer to the question: "Interviewer: Do you think some of the things they were talking about did have an effect on you? [...] With peer pressure like I don't know, that's probably going to be later on in high school or something but I think it's just you know not to get dragged into that you know. To be aware of it when you see it." (Student - Grade 8).

Participant's opinion towards the influence of the program Life Skills for Adolescents was very positive. When we asked a Grade 8 student if he had found the program interesting, his response was: "Yes" and, when the interviewer posed the question "Did you learn something? (translated from French), the same student replied: "Yes. Not to be influenced too fast..." (Student 5 - Grade 8, translated from French). Several other participants made similar comments.

What is more, respondents listed several strengths of the program [57]. Respondents reported that the program creates a comfortable forum for discussion, specifically on the positive and negative aspects of risky-behaviors and the process of decision making. A student reported that he had learned to make informed decisions: "Since you do not know what it is, you ask someone to explain you." (Student - Grade 8, translated from French).

\section{Discussion and Conclusion}

This study reports that adolescents generally do not think in terms of risk, but rather in terms of immediate experiences and gratification. They maintain rather abstract representations of the future; risky behaviors are experienced as positive and are part of adolescent social culture. Risks are often experienced in a group context where competition is enhanced by extreme risk [15]. A program like Life Skills for Adolescents can shape identity construction by raising awareness of the richness of cultural identity and resourcefulness for participants in their personal development and sense of community belonging [26].The importance of reflection and discussion before making any decision of whether or not to engage in risky behavior is addressed by Life Skills for Adolescents.

Prosocial health-enhancing behaviors which positively impact conventional socialization mechanisms and emotional growth are pretty straightforward, and include being academically diligent, being involved with family, community and faith-based activities [58].Through modeling, the equally important pro-social development and acquisition of moral and ethical behaviors, concurrent with sound judgment, can take place. Programs like Life Skills for Adolescents provide hands-on experience as rehearsals for future opportunities. While programs like the Lions Quest Program 'Life Skills for Adolescents' are helpful for adolescents learning to make healthy decisions regarding risky behaviors, promoting physical and mental health and reducing the likelihood of their using drugs or alcohol, these programs work best when combined with positive and healthy family environments of marital accord and positive and protective support for children [59]. Basically, by setting examples and promoting values, parents hope their children will, through emulation, move resiliently towards maturity $[60,61]$. Adolescents engage in risky behavior. It is clear that the program is gaining interest among young people 12-14 years, an age where potentially poor judgment by youth flourishes and is consolidated and peer influence takes a crucial role in their daily decisions. Educators and adults need not throw up their hands in surrender to adolescent 
risk-taking. Mature judgement as an emergent individual phenomenon, acknowledged and accepted as a component of the process of growth, may be affected by the influencing element of education [29].

More precisely, the findings of this study suggest that some program objectives were met satisfactorily. The theme of the growth of self-confidence predominates. The program also raises questions on how adolescents perceive of risks, make decisions and defend their views. These newly learned social skills, acquired through Life Skills for Adolescents, become tools to counter the use of alcohol and drugs and open new horizons for adolescent participants. Thus this study will contribute to the development of preventive programs, which can be adjusted for adolescent health and social policy development for minority language Francophones.

\section{REFERENCES}

[1] M. Jay. Liquidity Crisis: Zygmunt Bauman and the Incredible Lightness of Modernity, Theory, Culture \& Society, 27(6), 95-106, 2010.

[2] Z. Bauman. Liquid Modernity, Malden, MA: Polity Press, 2000.

[3] Catalano, A. Fagan, L. Gavin, M. Greenberg, I. Charles, D. Ross, D. Shek. Worldwide application of prevention science in adolescent health, The Lancet, 379(9826), 1653-1664, 2010.

[4] J. P. Moati, P. Peretti-Watel. Le principe de prévention, Collection de la République Eds. Lamartinière/ Le Seuil, Paris, France, 2009.

[5] A. Galvan, T. Hare, H. Voss, G. Glover, B. J. Casey. Risk-taking and the adolescent brain: who is at risk? Developmental Science, 10(2), F8-F14, 2007

[6] K. Chen, G. Yao. Investigating Adolescent Health-Related Quality of Life: From a Self-Identity Perspective, Social Indicators Research, 96(3), 403-415, 2010.

[7] P. Peretti-Watel. La société de risque (Nouvelle Édition), La Découverte, Paris, France, 2010.

[8] W. Pickett, S. Dostaler, W. Craig, I. Janssen, K. Simpson, S. Shelley, W. F. Boyce. Associations between risk behavior and injury and the protective roles of social environments: an analysis of 7235 Canadian school children, Injury Prevention, 12(2), 87-92, 2006.

[9] B. Stanton, M. Cole, J. Galbraith, J. J. Parental role vital to success of intervention aimed at reducing risky behavior in teens, DATA, The Brown University Digest of Addiction Theory \& Application, 24(3), 1-7, 2005.

[10] M. A. Miller-Day. Parent-Adolescent Communication about Alcohol, Tobacco, and Other Drug Use, Journal of Adolescent Research, 17(6), 604-616, 2002.

[11] V. F. Reyna, F. Farley, F. Risk and Rationality in Adolescent Decision Making: Implications for Theory, Practice, and
Public Policy, Psychological Science in the Public Interest (Wiley-Blackwell), 7(1), 1-44, 2006.

[12] G. Stein, A. Hussong. Social and Academic Expectations about High School for At-Risk Rural Youth, American Secondary Education, 36(1), 59-79, 2007.

[13] V. Nanhou, N. Audet. Les comportements à risque pour la santé liés au tabac, à l'alcool, aux drogues et aux jeux du hasard et d'argent. Qui les adopte? Qui les combine? Zoom Santé, Institut de la statistique du Québec, (36) 1-16, 2012.

[14] S. A. Hardy, S. W. Francis, B. L. Zamboanga, S. Kim, S.G. Anderson, L. F. Forthun. The Roles of Identity Formation and Moral Identity in College Student Mental Health, Health-risk Behaviors, and Psychological Well-Being, Journal of Clinical Psychology, 69(4), 364-382, 2013.

[15] D. Favresse. Le risque, une histoire de vie, Prospective Jeunesse Drogues / Santé /Prévention, 54, 10-16, 2000.

[16] E. Werner. Resilience Research- Past, Present, and Future: Resilience in children, families, and communities: linking context to practice and policy, Report on the 32nd Banff International Conference on Behavioral Science, 2000. Kluwer Academic/Plenum Publishers, Banff Alta, New York, 2005.

[17] N. Garmenzy, M. Rutter. Stress coping, and development in children, Mc Graw-Hill, New York, NY, 1983.

[18] S. S. Luthar. The Culture of Affluence: Psychological Costs of Material Wealth, Child Development. 74(6), 1581-1593, 2003.

[19] S. S. Luthar, S. J. Latendresse. Children of the Affluent, Current Directions in Psychological Science (Wiley-Blackwell), 14(1), 49-53, 2005.

[20] G. Puentes-Neuman, S.C. Cartier. Quelques constats au sujet de la recherche actuelle sur les élèves à risque, Revue de sciences de l'éducation. 33(3), 557-557, 2007.

[21] K. Pells. 'Risky lives': risk and protection for children growing-up in poverty, Development in Practice, 22(4), $562-573,2012$.

[22] S. T. DuRocher, E. M. Cummings. Parental Dysphoria and Children's Adjustment: Marital Conflict Styles, Children's Emotional Security, and Parenting as Mediators of Risk, Journal of Abnormal Child Psychology, 35(4), 627-639, 2007.

[23] F. Torche. The Effect of Maternal Stress on Birth Outcomes: Exploiting a Natural Experiment, Demography, 48(4), 1473-1491, 2011.

[24] T. Hotton, D. Haans. Health Reports, Statistics Canada, Catalogue 82-003, 15(3), 2004.

[25] L. Buckley, M. Sheehan, R. Chapman (2009). Adolescent Protective Behavior to Reduce Drug and Alcohol Use, Alcohol-related Harm and Interpersonal Violence, Journal of Drug Education, 39(3), 289-301, 2009.

[26] Ontario Ministry of Education. Je m'engage, tu t'engages: Guide de réflexion sur la relation enseignant-élève, Presses $\mathrm{du}$ Centre franco-ontarien de ressources pédagogiques, Ottawa, Canada, 59, 2008.

[27] J. Chein, A. Dustin, L. O’Brien, K. Uckert, L. Steinberg, L. 
Peers increase adolescent risk taking by enhancing activity in the brain's reward circuitry, Developmental Science, 14(2), 1-10, 2010.

[28] Bessant, J. (2008). Hard wired for risk: neurological science, 'the adolescent brain' and developmental theory, Journal of Youth Studies, 11(3), 347-360.

[29] L. Steinberg. Risk Taking in Adolescence: New Perspectives from Brain and Behavioral Science, Current Directions in Psychological Science, (4), 2007.

[30] S. K. Bathia, S. B. Bathia. Childhood and adolescent depression, American Family Physician, 75(1), 73-80, 2007.

[31] C. Gilligan, K. Kypri, D. Lubman (2012). Changing Parental Behavior to Reduce Risky Drinking Among Adolescents: Current Evidence and Future Directions, Alcohol \& Alcoholism, 47(3), 349-354, 2012.

[32] R. Bränström, E. Sjöström, S. Andréasson. Individual, group and community risk and protective factors for alcohol and drug use among Swedish adolescents, European Journal of Public Health, 18(1), 12-18, 2008.

[33] European Monitoring Center for Drugs and Drug Addiction (EMCDDA), Annual Report, 2003.

[34] H. Saab. Les comportements à risque chez les jeunes sur le plan de la santé. In W. Boyce (Ed.), Les jeunes au Canada : Leur santé et leur bien-être, 51-68, 2004. Online available from:

http://www.phac-aspc.gc.ca/hp-ps/dca-dea/publications/hbsc $-2004 /$ index-fra.php

[35] C. Narbonne-Fortin, G. Racine. Comportement et santé : Alcool. In L. Picard \& G. Allaire (Eds.), Deuxième rapport sur la santé des francophones de l'Ontario, p.77-87, 2005. Online available from: http://www.google.ca/url?sa=t\&rct=j\&q=\&esrc=s\&source= web\&cd=1\&ved=0CB8QFjAA\&url=http $\% 3 \mathrm{~A} \% 2 \mathrm{~F} \% 2 \mathrm{Fww}$ w.ahrni-irras.ca\%2Findex.php\%3Foption\%3Dcom sobipro \%26task\%3Ddownload.file\%26fid\%3D269.1071\%26sid\%3 D102\%26Itemid\%3D115\&ei=wHsIVbG1D5T-yQSjpoGgA w\&usg=AFQjCNFGO1r7sfKsHT2cyDonpxQP 2ICtw\&sig2 $=$ YT4K05tXnkSLHJMJidZOzA

[36] S. Atav, G. A. Spencer. Health risk behaviors among adolescents attending rural, suburban, and urban schools: A comparative study, Family \& Community Health, 25, 53-64, 2002.

[37] C. W. Rishel, L. Cottrell, T. Kingery. Preventing Adolescent Risk Behavior in the Rural Context: An Integrative Analysis of Adolescent, Parent, and Provider Perspectives, Journal of Family Social Work, 15(5), 401-416, 2012.

[38] D. B. Henry, K. Kobus. Early adolescent social network and substance use, Journal of Early Adolescence, 27(3), 346-362, 2007.

[39] L. Guyon, L. Desjardins, L. L'alcool et les drogues chez les élèves Québécois de 12 à 18 ans. In L. Guyon, S. Brochu et M. Landry (Ed.), Les jeunes et les drogues, 1-38, Presses de l’Université Laval, 2005, Québec, Canada.

[40] Alcoholism \& Drug Abuse Weekly. More good news for youth in annual survey, but treatment gap persists, Alcoholism \& Drug Abuse Weekly, 18(35), 1-5, 2006.

[41] E.M. Adlaf, A. Paglia-Boak. Drug use among Ontario students 1977-2007: Detailed OSDUHS findings, 2007. Online available from:

http://www.camh.ca/en/research/news and publications/ont ario-student-drug-use-and-health-survey/Documents/2011\% 20OSDUHS\%20Docs/2011OSDUHS_Detailed_DrugUseRe port_2.pdf

[42] S. Luthar, S.J. Latendresse. Children of the Affluent, Current Directions in Psychological Science (Wiley-Blackwell), 14(1), 49-53, 2005.

[43] R. R. Levesque. Reflections on a Legendary Contribution to the Empirical Study of Adolescence, Journal of Youth \& Adolescence, 36(1), 1-4, 2007.

[44] S. Burnett, S. Blakemore, S. The Development of Adolescent Social Cognition, Annals of the New York Academy of Sciences, 1167, 51-56, 2009.

[45] S. Collishaw, B. Maughan, L. Natarajan, A. Pickles. Trends in adolescent emotional problems in England: a comparison of two national cohorts twenty years apart, Journal of Child Psychology \& Psychiatry and Allied Disciplines, 51(8), 885-894, 2010.

[46] B. V. Marin, D. B. Kirby, E. S. Hudes, K. K, Coyle, C. A. Gomez. Boyfriends, Girlfriends, and teenagers' risk of sexual involvement, Perspectives on Sexual \& Reproductive Health, 38, 76-83, 2007.

[47] K. Wilson, M. Asbridge, S. Kisely, D. Langille. Associations of Risk of Depression with Sexual Risk Taking Among Adolescents in Nova Scotia High Schools. Canadian Journal of Psychiatry, 55(9), 577-585, 2010.

[48] A. Bandura, A. Self-efficacy: the exercise of control, W.H. Freeman, New-York, NY, 1997.

[49] N. Wille, S. Bettge, U. Ravens-Sieberer. Risk and protective factors for children's and adolescents' mental health: results of the BELLA study, European Child \&Adolescent Psychiatry, 17, 133-147, 2008.

[50] A. Bandura, G. Caprara, C. Barbaranelli, M. Gerbino, C. Pastorelli. Role of Affective Self-Regulatory. Efficacy in Diverse Spheres of Psychosocial Functioning, Child Development, 74(3), 769-782, 2003.

[51] D. Jeffrey, D. Le Breton, J. Levy (Dir.). Jeunesse à risque: Rite et passage, Les Presses de l'Université Laval, Québec, Canada, 2005.

[52] M. Eisen, G. K. Zellman, H. A. Massett, D.M. Murray. Evaluating the Lions-Quest "Skills for Adolescents" drug education program: First-year behavior outcomes, Addictive Behaviors. 27(4), 619-632, 2002.

[53] R. Mayer, F. Ouellet, M.-C. Saint-Jacques, D. Turcotte. Méthodes de recherche en intervention sociale. Boucherville, Gaëtan Morin (Ed.), Québec, Canada, 2000.

[54] QSR International Qualitative Data Analysis, Sofware History, 2007.

[55] M.A. Huberman, M. B. Miles. Qualitative Data Analysis: A Methods Sourcebook, $3^{\text {rd }}$ Edition, Sage Publications Inc., Thousand Oaks, CA, 2014.

[56] P. Paillé, A. Mucchielli. L'analyse qualitative en sciences humaines et sociales, Armand Colin, Paris, France, 2003. 
[57] M. Drolet, R. Leblanc, D. Ducharme, L. Arcand (2011). Les clefs pour l'adolescence, un programme de promotion de la santé et de la santé mentale: un enjeu du développement social positif des adolescents en milieu scolaire, Rapport d'étude, Ottawa, Canada, 2011. Online available from: $\mathrm{http} / / /$ socialsciences.uottawa.ca/crecs/fra/documents/LesCles pourladolescence.pdf

[58] R. Jessor, M. S. Turbin, F. M. Costa. Predicting Developmental Change in Healthy Eating and Regular Exercise among Adolescents in China and the United States: The Role of Psychosocial and Behavioral Protection and Risk, Journal of Research on Adolescence (Wiley-Blackwell),
20(3), 707-725, 2010.

[59] R. Loeber, Y. Yin, S. J. Anderson, L. C. Schmidt, A. Crawford. Stability of family interaction from 6 to 18 , Journal of Abnormal Child Psychology, 28(4), 353-369, 2000.

[60] D. Barni, S. Ranieri, E. Scabini, R. Rosnati. Value transmission in the family: do adolescents accept the values their parents want to transmit? Journal of Moral Education, 40(1), 105-121, 2011.

[61] J. B. Kelly. Changing Perspectives on Children's Adjustment Following Divorce, Childhood, 10(2), 251, 2003. 